\title{
Predicting high blood metal ion concentrations following hip resurfacing
}

\author{
Gulraj S. Matharu, Fiona Berryman, Lesley Brash, Paul B. Pynsent, Ronan B.C. Treacy, David J. Dunlop \\ Arthroplasty Department, The Royal Orthopaedic Hospital, Birmingham - UK
}

\begin{abstract}
Purpose: To determine whether gender, femoral head size, acetabular inclination, and time since surgery predicted high blood metal ion concentrations following Birmingham Hip Resurfacing (BHR).

Methods: BHR patients with unilateral bearings at one specialist centre with blood cobalt and chromium concentrations measured up to May 2013 were included. This comprised a mixed (at-risk) group including symptomatic patients and asymptomatic individuals with specific clinical and/or radiological findings. Blood sampling was at a mean of 7.5 years (range 1-15.4 years) postoperatively.

Results: Of 319 patients (mean age 49.3 years; $53 \%$ male), blood metal ions greater than $7 \mu$ g/l were observed in $9 \%(n=28)$. Blood metal ions were significantly higher in females $(p<0.001)$, femoral head sizes $\leq 48 \mathrm{~mm}(p<0.01)$, and cup inclinations $>55^{\circ}(\mathrm{p}<0.001)$. Linear regression demonstrated femoral head size was responsible for the highest proportion of variance in blood metal ions (cobalt $p<0.001, R^{2}=8 \%$; chromium $p<0.001, R^{2}=11 \%$ ). Analysis of femoral head size and inclination together demonstrated $36 \%$ of BHRs with head sizes of 38-44 mm and inclination $>55^{\circ}$ had blood metal ions $>7 \mu \mathrm{g} / \mathrm{l}$. BHR 10 -year survival for this at-risk group was $91 \%$ (95\% confidence intervals $86.0 \%-95.0 \%$ ) with 30 hips revised.

Conclusions: If blood metal ions are used to screen hip resurfacing patients for adverse reactions to metal debris it is recommended those with small femoral head sizes $(38-44 \mathrm{~mm})$ and high acetabular inclinations $\left(>55^{\circ}\right)$ are targeted. These findings require validation in other cohorts as they may not be applicable to all hip resurfacing devices given the differences in radial clearance, coverage arc, and metallurgy.
\end{abstract}

Keywords: Hip resurfacing, Blood metal ions, Head size, Cup inclination, Gender

\section{Introduction}

Metal-on-metal hip resurfacing can produce excellent clinical outcomes in young individuals with hip arthritis up to 14 years postoperatively when patients and implants are carefully selected (1-5). Despite these promising results, some patients will develop problems related to high bearing wear $(6,7)$. Patients who develop adverse reactions to metal debris (ARMD) may require revision surgery, though shortterm outcomes following revision are reportedly poor (8-10). Outcomes following revision may be influenced by the degree of soft-tissue destruction. Therefore, early intervention may result in more favourable outcomes following revision

\footnotetext{
Accepted: April 8, 2015

Published online: June 6, 2015

Corresponding author:

Gulraj Matharu

The Royal Orthopaedic Hospital

Bristol Road South

Northfield

Birmingham

West Midlands, B31 2AP, UK

gsm@doctors.org.uk
}

(11). To achieve this, patients who develop ARMD must be identified early using appropriate investigations when the condition is suspected.

Blood metal ion concentrations are an accepted surrogate marker of metal-on-metal bearing wear, and therefore can be useful in identifying patients with ARMD (12). A blood test is quick and minimally invasive. Recommendations from the Medical and Healthcare Products Regulatory Agency (MHRA) suggest that provided the implant has not been recalled blood metal ion sampling should only be performed in patients with metal-on-metal hip resurfacings who are symptomatic (13). However, ARMD lesions have been observed in asymptomatic patients with well-functioning hip resurfacings $(14,15)$.

If symptoms are not helpful in identifying patients with ARMD there are 2 options. The first would be to perform blood metal ion sampling in all hip resurfacing patients. This is unfavourable because most patients will have negative results, yet will suffer unnecessary anxiety and concern. Also there would be huge cost and resource implications for institutions. The second strategy would involve targeted screening of patients at increased risk of developing ARMD, such as female patients, those with small femoral component sizes, acetabular components outside the recommended 'safe-zone', and resurfacings performed for hip dysplasia $(7,16-19)$. It would 
be beneficial to determine which combination of factors optimally identifies hip resurfacing patients at risk of developing ARMD so this subgroup can be screened using blood metal ion sampling.

This study aimed to determine whether high blood metal ion concentrations following Birmingham Hip Resurfacing could be predicted by gender, femoral component head size, acetabular component inclination, or time since index operation.

\section{Methods}

\section{Study design, inclusion criteria, and patient demographics}

This prospective cohort study was undertaken at a single specialist arthroplasty centre and was registered with the institutional review board. Birmingham Hip Resurfacings (BHRs; Smith \& Nephew, Warwick, United Kingdom) implanted at this centre between August 1997 and May 2013 with measured blood metal ion concentrations were eligible for inclusion. Information regarding patient selection and operative technique for BHR surgery performed at this institution has been described (20).

During the study period 3295 BHRs were implanted. Blood metal ion sampling was performed in 606 patients with 738 BHRs (22\%). Patients with bilateral hip replacements were excluded (378 hips) because of difficulties associated with interpreting raised blood metal ions in the presence of 2 hip bearings $(5,11)$. Patients were also excluded if they met any of the following criteria: the BHR was revised prior to blood sampling (37 BHRs excluded); blood sampling was less than 1-year postoperatively (2 BHRs excluded); no information was available on acetabular inclination angle (2 BHRs excluded). Therefore 319 BHRs were eligible for final study inclusion from the 738 BHRs (43\%) with blood metal ions measured during the study period (Tab. I). Operations were performed by 12 surgeons, with 1 designing surgeon (RBCT) performing most $(n=87 ; 27 \%)$. Procedures were performed using a posterior $(90 \%)$ or antero-lateral $(10 \%)$ surgical approach.

\section{Description of follow-up routine}

This institution's standard follow-up regimen is to review all patients at 6 weeks postoperatively in clinic, and subsequently at $1,5,10$, and 15 years following BHR surgery. Each consultation consists of clinical examination, anteroposterior pelvic radiographs, and completion of the Oxford Hip Score (OHS) questionnaire (21). Blood metal ion sampling was not performed prior to 2010.

After the MHRA published concerns regarding ARMD associated with metal-on-metal hips $(13,22)$ this institution deemed it unnecessary to recall all BHR patients for clinical review because: 1 ) good outcomes with this device have been achieved at numerous centres $(2-5) ; 2$ ) the BHR has significantly lower failure rates for ARMD compared to other devices $(7,23)$; and 3$)$ the BHR has not been recalled.

In 2010 all patients who had undergone BHR surgery at this centre were contacted by post. All patients with hip symptoms regardless of severity attended an urgent clinical review, which included blood metal ion sampling. The remaining asymptomatic patients were reviewed according to
TABLE I - Summary of the study cohort

\begin{tabular}{|c|c|c|}
\hline & & Cohort ( $n=319$ hips) \\
\hline \multirow[t]{2}{*}{ Gender } & Male & $169(53 \%)$ \\
\hline & Female & $150(47 \%)$ \\
\hline $\begin{array}{l}\text { Age at index } \\
\text { resurfacing }\end{array}$ & Mean (range) in years & $49.3(14.3-75.0)$ \\
\hline \multirow[t]{8}{*}{ Diagnosis } & Primary osteoarthritis & $239(75 \%)$ \\
\hline & Developmental dysplasia & $25(8 \%)$ \\
\hline & Avascular necrosis & $6(2 \%)$ \\
\hline & Inflammatory arthritis & $11(3 \%)$ \\
\hline & SUFE & $8(3 \%)$ \\
\hline & Perthes & $9(3 \%)$ \\
\hline & Hip trauma & $4(1 \%)$ \\
\hline & Other causes & $17(5 \%)$ \\
\hline $\begin{array}{l}\text { Follow-up } \\
\text { time from } \\
\text { surgery to } \\
\text { blood } \\
\text { metal ion } \\
\text { sampling }\end{array}$ & Mean (range) in years & $7.5(1.0-15.4)$ \\
\hline \multirow{2}{*}{$\begin{array}{l}\text { Blood } \\
\text { metal ion } \\
\text { concentration }\end{array}$} & \multirow{2}{*}{$\begin{array}{l}\text { Median } \\
\text { (interquartile range) } \\
\text { in } \mu \mathrm{g} / \mathrm{l}\end{array}$} & Co 1.06 (0.71-1.89) \\
\hline & & Cr $1.56(1.09-2.65)$ \\
\hline \multirow{10}{*}{$\begin{array}{l}\text { Femoral } \\
\text { component } \\
\text { size }\end{array}$} & $38 \mathrm{~mm}$ & $1(0 \%)$ \\
\hline & $42 \mathrm{~mm}$ & $41(13 \%)$ \\
\hline & $44 \mathrm{~mm}$ & $2(1 \%)$ \\
\hline & $46 \mathrm{~mm}$ & $93(29 \%)$ \\
\hline & $48 \mathrm{~mm}$ & $13(4 \%)$ \\
\hline & $50 \mathrm{~mm}$ & $101(32 \%)$ \\
\hline & $52 \mathrm{~mm}$ & $11(3 \%)$ \\
\hline & $54 \mathrm{~mm}$ & $53(17 \%)$ \\
\hline & $56 \mathrm{~mm}$ & $1(0 \%)$ \\
\hline & $58 \mathrm{~mm}$ & $3(1 \%)$ \\
\hline \multirow{4}{*}{$\begin{array}{l}\text { Acetabular } \\
\text { component } \\
\text { inclination }\end{array}$} & Mean inclination & $47.0^{\circ}\left(22.3^{\circ}-73.4^{\circ}\right)$ \\
\hline & Less than 35 degrees & $23(7 \%)$ \\
\hline & 35-55 degrees & $251(79 \%)$ \\
\hline & $\begin{array}{l}\text { Greater than } 55 \\
\text { degrees }\end{array}$ & $45(14 \%)$ \\
\hline \multirow[t]{7}{*}{$\begin{array}{l}\text { Abnormal } \\
\text { radiology* }\end{array}$} & $\begin{array}{l}\text { Hips with any } \\
\text { abnormality }\end{array}$ & $84(26 \%)$ \\
\hline & $\begin{array}{l}\text { Cup malposition } \\
\left(<35^{\circ} \text { or }>55^{\circ}\right)\end{array}$ & $68(21 \%)$ \\
\hline & Lucent lines (femoral) & $16(5 \%)$ \\
\hline & Lucent lines (acetabular) & $8(3 \%)$ \\
\hline & Osteolysis (femoral) & $2(1 \%)$ \\
\hline & Osteolysis (acetabular) & $3(1 \%)$ \\
\hline & Femoral neck narrowing & $2(1 \%)$ \\
\hline
\end{tabular}

$\mathrm{Co}=$ cobalt $; \mathrm{Cr}$ = chromium; SUFE = slipped upper femoral epiphysis. *13 of 84 hips had more than one radiological abnormality. 
TABLE II - Indications for measuring blood metal ion concentrations in patients following Birmingham Hip Resurfacing performed at this centre

Symptomatic patients

(regardless of symptom severity)

Asymptomatic patients
- All patients underwent blood metal ion sampling

- Blood metal ion sampling performed in asymptomatic patients at routine clinical review with one or more of the following:

1. Patient concerns about implant and/or wishes to have a blood test in light of media and press attention

2. Patient has bilateral metal-on-metal hip bearings in-situ

3. Patient has experienced episodes of ipsilateral hip squeaking, clicking, grating, locking, clunking, or other noises, and/or these can be elicited during clinical examination

4. Patient has radiographic evidence suggestive of implant failure or suboptimal function which include component malposition (especially high cup inclination and/or excessive anteversion), osteolysis, radiolucent lines, and/or femoral neck thinning the standard follow-up intervals. The indications for measuring blood metal ions in asymptomatic BHR patients at this centre (Tab. II) have evolved since 2010 due to the expanding evidence-base $(11,24)$. The present cohort $(n=319)$ therefore represents a mixed (at-risk of ARMD) group of symptomatic patients and asymptomatic individuals with specific clinical and/or radiological findings.

\section{Blood metal ion sampling}

Whole blood was collected for blood metal ion analysis. Venous blood was obtained using a 23-gauge stainless steel needle connected to a vacutainor system (Vacuette; Greiner Bio-One $\mathrm{GmbH}$, Kremsmünster, Austria) and collected in trace element tubes containing sodium heparin. All samples were then transported to an external laboratory approved by the MHRA for blood metal ion analysis. Cobalt (Co) and chromium $(\mathrm{Cr})$ concentrations were measured in all samples using an inductively-coupled plasma mass spectrometer (Agilent 7500 cx, Agilent Technologies Inc., Santa Clara, US). The limit of detection and the reporting limit were $0.06 \mu \mathrm{g} / \mathrm{l}$ and $0.6 \mu \mathrm{g} / \mathrm{l}$ respectively. Blood metal ions were considered raised if $\mathrm{Co}$ and/or $\mathrm{Cr}$ concentrations were greater than the MHRA upper limit of $7 \mu \mathrm{g} / \mathrm{l}(13)$.

\section{Description of outcome measures}

All study data except for radiographic data were extracted from the institution's prospectively maintained database (MySQL database, Oracle Corporation, Redwood Shores, California). The database contains details on patient demographics, surgery performed, blood metal ion concentrations, and any complications during follow-up.

Acetabular component inclination was measured in each anteroposterior pelvic radiograph using the teardrop line for reference as described (25). Acetabular inclination was measured by 2 authors (GSM and DJD) after excellent interobserver and intra-observer reliability was confirmed following both authors measuring a sample of 30 such radiographs (no significant difference between the surgeons' measurements were found with $p=0.82$ and intra- and inter-observer $95 \%$ limits of agreement of $-2.2^{\circ}$ to $1.6^{\circ}$ and $-2.5^{\circ}$ to $3.5^{\circ}$ respectively; $95 \%$ confidence intervals for intraclass coefficients were 0.994-0.998 and 0.984-0.994 respectively) (26). All radiographs were assessed for osteolysis, radiolucencies, and femoral neck thinning as previously described (27-29).

\section{Statistical analysis}

All analyses were performed using $R$ (30). Linear regression and $t$-tests were performed to investigate relationships between the base 10 logarithm ( $\log$ ) of blood metal ion concentrations and the 4 covariates (gender, femoral component head size, acetabular component inclination, and time since index operation). The logarithm was necessary to transform the asymmetric blood metal ion distributions so that the residuals in the regression models were more normally distributed; this assumption was checked by examining the regression diagnostic plots. The logarithmic transformation has often been used in previous studies analysing similar data $(31,32)$. Adjusted $R^{2}$ was also calculated to give the percentage of variance in log blood metal ion concentrations explained by the models. Femoral head sizes were grouped $(38 / 42 / 44 \mathrm{~mm}(\mathrm{n}=44), 46 / 48 \mathrm{~mm}$ ( $\mathrm{n}=106), 50 / 52 \mathrm{~mm}(\mathrm{n}=112), 54 / 56 / 58 \mathrm{~mm}(\mathrm{n}=57)$ ) for $t$-testing with multiple comparisons. Similarly, acetabular inclination angles were grouped $\left(<35^{\circ}(n=23), 35^{\circ}-55^{\circ}(n=251)\right.$, $\left.>55^{\circ}(n=45)\right)$ as previously described (18). The Holm method was used for adjusting the $p$-values in this $t$-testing to allow for multiple comparisons.

Cumulative BHR survival was determined using the KaplanMeier method. The endpoint for survival analysis was revision surgery, defined as removal or exchange of either the femoral or acetabular component, or both. Patients not undergoing revision surgery were censored after their last contact with the hospital or after death. A Cox-proportional hazards model was used to compare differences in BHR survival between patients with high $(>7 \mu \mathrm{g} / \mathrm{l})$ and low $(\leq 7 \mu \mathrm{g} / \mathrm{l})$ blood metal ions. A p-value of less than 0.05 was considered statistically significant with confidence intervals $(\mathrm{Cl})$ set at the $95 \%$ level. 

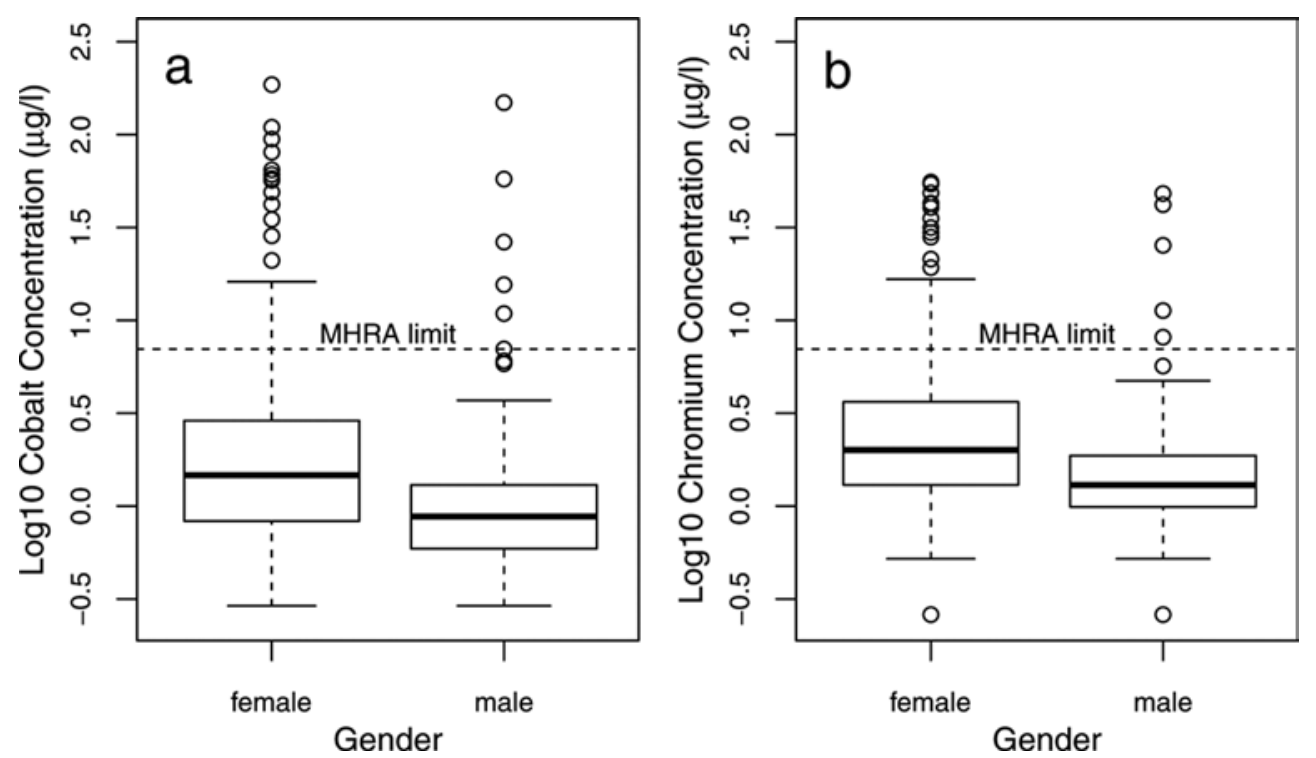

Fig. 1 - a) and b) Box plots for gender following BHR of a) $\log _{10}$ whole blood cobalt concentration and b) $\log _{10}$ whole blood chromium concentration. The MHRA upper limit of $7 \mu \mathrm{g} / \mathrm{l}$ is indicated by the dashed horizontal line. The width of each box is proportional to the number of hips in the group.

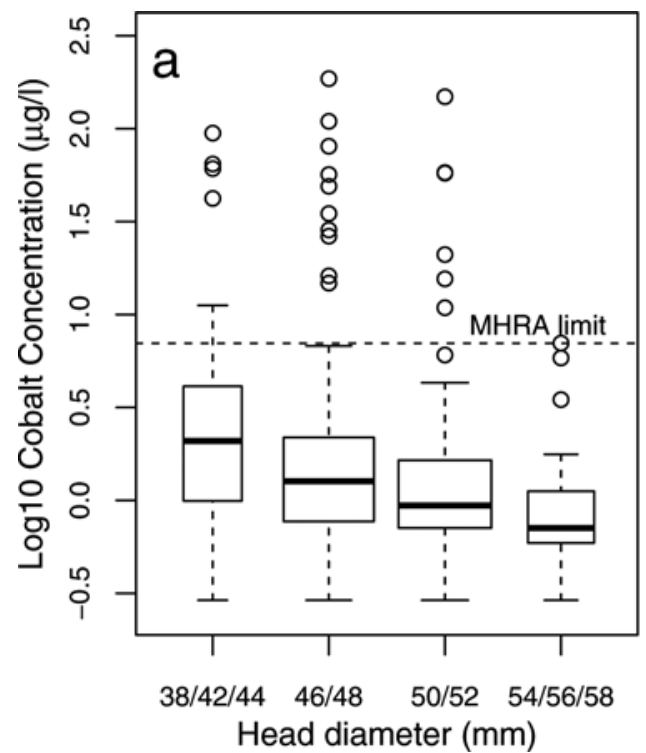

Results

Median (interquartile-range) blood Co and $\mathrm{Cr}$ concentration for the 319 unilateral BHR patients were $1.06 \mu \mathrm{g} / \mathrm{I}(0.71-$ $1.89 \mu \mathrm{g} / \mathrm{l})$ and $1.56 \mu \mathrm{g} / \mathrm{l}(1.09-2.65 \mu \mathrm{g} / \mathrm{l})$ respectively. In the patients with bilateral implants excluded from further analysis, median (interquartile-range) blood $\mathrm{Co}$ and $\mathrm{Cr}$ concentrations were $2.24 \mu \mathrm{g} / \mathrm{I}(1.24-3.95 \mu \mathrm{g} / \mathrm{l})$ and $2.34 \mu \mathrm{g} / \mathrm{l}(1.61-4.42 \mu \mathrm{g} / \mathrm{l})$ respectively. Log blood metal ion concentrations were significantly higher in the bilateral group compared to the unilateral group ( $p<0.00001$ for both Co and $\mathrm{Cr}$ ).

Of the 319 unilateral BHRs, blood metal ions greater than recommended thresholds of $7 \mu \mathrm{g} / \mathrm{l}$ were observed in $28 \mathrm{pa}-$ tients (9\%). Blood metal ions greater than $7 \mu \mathrm{g} / \mathrm{l}$ were observed in $15 \%(22 / 150)$ of females compared to $4 \%(6 / 169)$ of males. Females had significantly higher log blood metal ion concentrations than males ( $t$-test with $p<0.001$ for both Co and $\mathrm{Cr}$; Fig. 1).

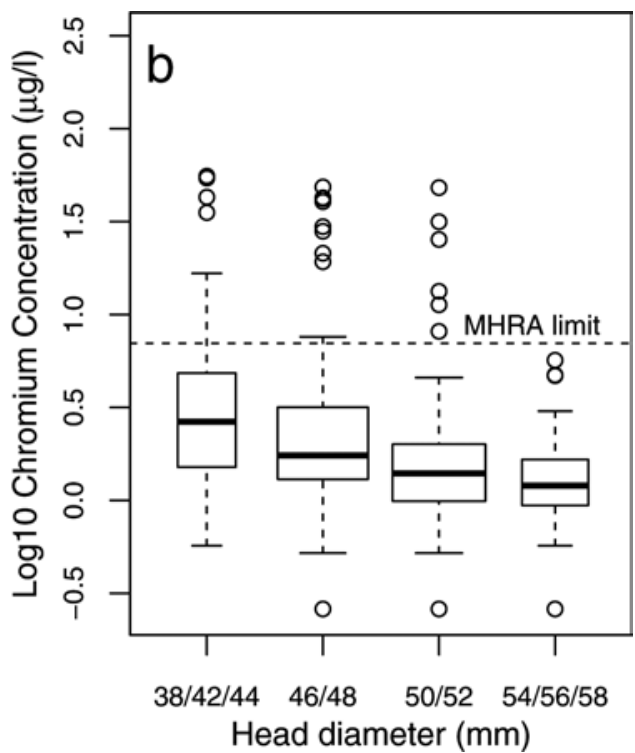

Fig. 2 - a) and b) Box plots for femoral head diameter following BHR of a) $\log _{10}$ whole blood cobalt concentration and b) $\log _{10}$ whole blood chromium concentration. The MHRA upper limit of $7 \mu \mathrm{g} / \mathrm{l}$ is indicated by the dashed horizontal line. The width of each box is proportional to the number of hips in the group.
The 38/42/44 $\mathrm{mm}$ and $46 / 48 \mathrm{~mm}$ femoral head size groups had significantly higher log blood metal ion concentrations than the $50 / 52 \mathrm{~mm}$ and $54 / 56 / 58 \mathrm{~mm}$ groups $(\mathrm{p}<0.01$ for both $\mathrm{Co}$ and $\mathrm{Cr}$; Fig. 2). Log blood metal ion concentrations were significantly higher in cups with inclination $>55^{\circ}$ compared to those with inclination of $35^{\circ}-55^{\circ}(p<0.001$ for both Co and Cr; Fig. 3). There were 84 (26\%) BHRs exhibiting abnormal radiology (Tab. I) and log blood metal ion concentrations were significantly higher in this group compared to the normal radiology group ( $p=0.002$ for both Co and $\mathrm{Cr}$ ). Blood metal ions above $7 \mu \mathrm{g} / \mathrm{l}$ were observed in 14 of 84 BHRs with abnormal radiology. The most frequent abnormal radiological feature in these 14 hips with raised metal ions was acetabular component inclination outside $35^{\circ}-55^{\circ}$ (11 hips). Of these malpositioned hips, 1 also demonstrated both femoral lucency (zone 1) and acetabular osteolysis (zone 1), and another hip had acetabular lucencies (zones 1 and 2). The other 3 hips with abnormal radiology, raised blood 

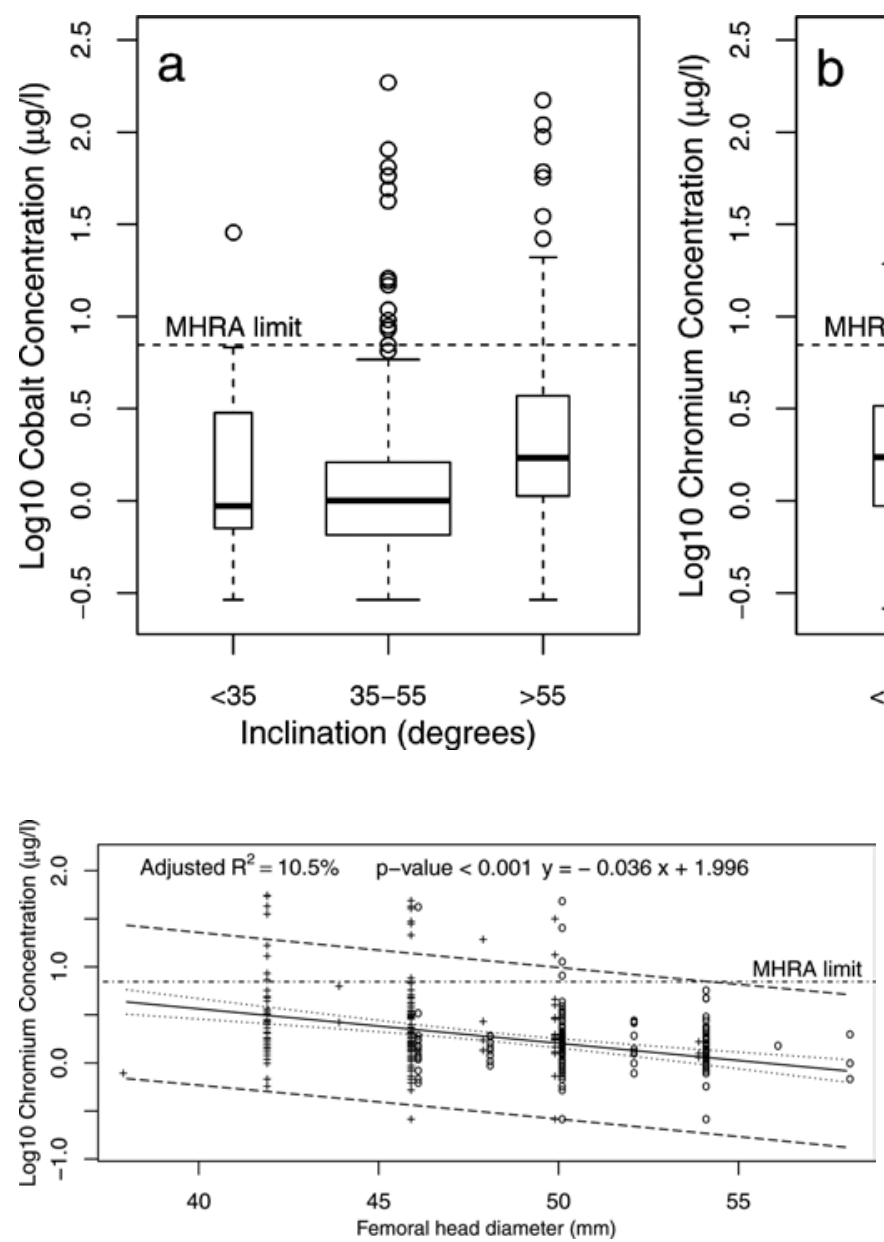

Fig. 4 - $\log _{10}$ whole blood chromium concentration modelled on femoral head diameter with regression line (solid), 95\% confidence limits (dotted) and 95\% prediction limits (dashed). The MHRA upper limit of $7 \mu \mathrm{g} / \mathrm{l}$ is indicated by the dot-dashed horizontal line. Hips from females are indicated by $a$ ' $t$ ' and from males by an ' 0 '. Similar results were obtained for $\log _{10}$ blood cobalt concentrations (Adjusted $\mathrm{R}^{2}=8 \%$, $\mathrm{p}$-value $<0.001, \mathrm{y}=-0.040 \mathrm{x}+2.037$ ).

metal ions, but normal acetabular component inclinations all showed evidence of radiographic lucency ( 1 in acetabular and femoral zones 1 , and 2 hips with acetabular lucency in zone 2). All radiological lucent lines were non-progressive on serial radiographs and patients were asymptomatic.

Univariate linear regression modelling demonstrated that the highest proportion of variance in the logarithms of blood metal ion concentrations was explained by femoral head size (Co $p<0.001, R^{2}=8 \%$; Cr $p<0.001, R^{2}=11 \%$; Fig. 4) followed by gender (Co $\left.p<0.001, R^{2}=8 \% ; C r p<0.001, R^{2}=10 \%\right)$, inclination (Co $p<0.001, R^{2}=4 \%$; $\mathrm{Cr} p<0.001, R^{2}=4 \%$; Fig. 5) and time since index operation (Co $p=0.032, R^{2}=1 \%$; $C r$ $\left.p=0.255, R^{2}<1 \%\right)$. Multivariate linear regression modelling demonstrated the best fitting models for predicting log blood cobalt and chromium levels were additive ones combining femoral head size, gender, time since index operation and an interaction term between acetabular inclination and time since index operation ( $\operatorname{Co} p<0.001, R^{2}=13 \%$; $\operatorname{Cr} p<0.001$, $\left.R^{2}=15 \%\right)$.

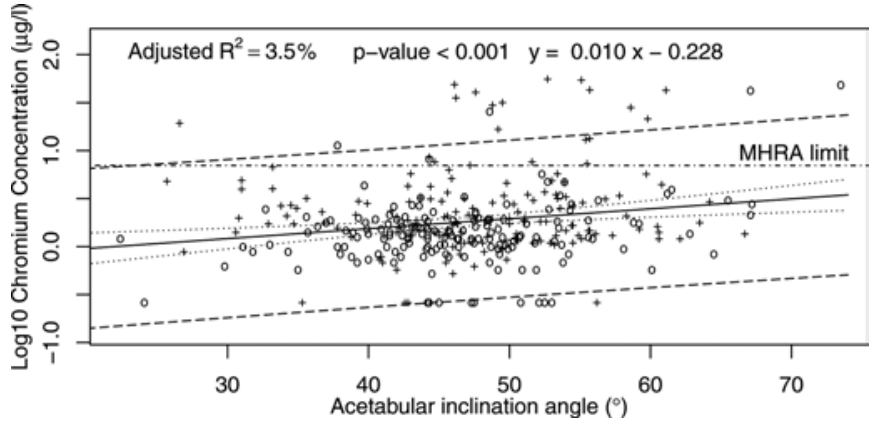

Fig. 5 - $\log _{10}$ whole blood chromium concentration modelled on acetabular inclination angle with regression line (solid), 95\% confidence limits (dotted) and $95 \%$ prediction limits (dashed). The MHRA upper limit of $7 \mu \mathrm{g} / \mathrm{l}$ is indicated by the dot-dashed horizontal line. Hips from females are indicated by a ' + ' and from males by an ' $O$ '. Similar results were obtained for $\log _{10}$ blood cobalt concentrations (Adjusted $\mathrm{R}^{2}=4 \%, \mathrm{p}$-value $<0.001, \mathrm{y}=0.013 \mathrm{x}-0.515$ ).

Analysis of femoral head size and acetabular inclination together demonstrated that BHRs with high inclinations and small femoral head sizes were the most predictive for identifying patients with blood metal ion concentrations above the recommended $7 \mu \mathrm{g} / \mathrm{l}$ threshold. Blood metal ion concentrations above $7 \mu \mathrm{g} / \mathrm{l}$ were observed in $36 \%$ of BHRs with femoral head sizes of $38-44 \mathrm{~mm}$ and acetabular inclination $>55^{\circ}$ (Tab. III).

Hip dysplasia is more prevalent in females who, in general, have smaller femoral head sizes and higher inclination angles due to difficulty in positioning the acetabular component. An exact Fisher test on the proportions of hips with blood metal ions $>7 \mu \mathrm{g} / \mathrm{l}$ demonstrated no significant difference (odds ratio $=2.20,95 \% \mathrm{Cls}=0.5-7.51, \mathrm{p}=0.251$ ) between BHRs implanted for primary osteoarthritis (19/239 BHRs above MHRA upper limit) and BHRs implanted for developmental hip dysplasia (4/25 BHRs above MHRA upper limit).

All 28 patients with blood metal ions above $7 \mu \mathrm{g} / \mathrm{l}$ were investigated with cross-sectional imaging (ultrasound for 
TABLE III - Number of Birmingham Hip Resurfacing within each femoral head size and acetabular inclination angle group and the percentage exceeding the recommended MHRA upper limit $(7 \mu \mathrm{g} / \mathrm{l})$ for either cobalt or chromium

\begin{tabular}{lccc}
\hline & \multicolumn{3}{c}{ Inclination angle (degrees) } \\
\hline Head size (mm) & $<35$ & 35 to 55 & $>55$ \\
$38 / 42 / 44$ & $\mathrm{n}=3$ & $\mathrm{n}=30$ & $\mathrm{n}=11$ \\
& $0 \%$ & $17 \%$ & $36 \%$ \\
$46 / 48$ & $\mathrm{n}=11$ & $\mathrm{n}=79$ & $\mathrm{n}=16$ \\
& $9 \%$ & $9 \%$ & $25 \%$ \\
$50 / 52$ & $\mathrm{n}=5$ & $\mathrm{n}=92$ & $\mathrm{n}=15$ \\
& $0 \%$ & $4 \%$ & $13 \%$ \\
$54 / 56 / 58$ & $\mathrm{n}=4$ & $\mathrm{n}=50$ & $\mathrm{n}=3$ \\
& $0 \%$ & $2 \%$ & $0 \%$ \\
\hline
\end{tabular}

symptomatic patients, and metal artifact reduction sequence magnetic resonance imaging for asymptomatic patients). Following cross-sectional imaging, 16 revisions have been performed (15 ARMD and 1 periprosthetic fracture) in the 28 patients with blood metal ions above $7 \mu \mathrm{g} / \mathrm{l}$. The indications for ARMD revision have evolved over time and between surgeons given no evidence-based guidelines provide thresholds for revision (13). Generally patients with blood metal ions above $7 \mu \mathrm{g} / \mathrm{l}$ and abnormal cross-sectional imaging (periprosthetic effusions and fluid collections) underwent revision regardless of symptoms (Tab. IV). However, patients with increasing blood metal ions and persistent hip pain were also considered for revision by some surgeons despite normal cross-sectional imaging (Tab. IV).

Of the remaining $12 \mathrm{BHR}$ patients with high blood metal ions, 9 had normal cross-sectional imaging and remain under annual clinical surveillance (repeat blood metal ion sampling and imaging). The remaining 3 asymptomatic BHR patients with high blood metal ions had abnormal cross-sectional imaging (effusions and fluid collections ranging from $5.5 \mathrm{~cm}^{3}$ to $75 \mathrm{~cm}^{3}$ ) but have refused to undergo revision surgery. These patients remain under 6-monthly review (repeat blood metal ion sampling and imaging).

Revisions have also been performed in 14 patients with blood metal ion levels $\leq 7 \mu \mathrm{g} / \mathrm{l}$ (5 ARMD, 3 unexplained pain, 2 aseptic cup loosening, 2 aseptic stem loosening, 1 femoral head osteonecrosis, and 1 osteolysis of the femoral neck). The 30 revisions performed in patients at risk of ARMD $(n=319)$ were at a mean of 8.9 years (range 4.1 15.0 years) from index BHR. For survival analysis mean patient follow-up was 8.0 years (range $1.0-16.4$ years). Cumulative 10 -year survival for all BHRs $(n=319)$ was $91 \%$ (95\% Cl 86.0\%-95.0\%; 107 hips at risk). The cumulative 10year survival for BHRs with blood metal ions $>7 \mu \mathrm{g} / \mathrm{l}(\mathrm{n}=28)$ was $86.0 \%$ (95\% Cl 77.7\%-97.4\%) compared to $97.9 \%(95 \%$ $\mathrm{Cl}$ 96.3\%-99.5\%) for BHRs with ions $\leq 7 \mu \mathrm{g} / \mathrm{I}(\mathrm{n}=291$ ) (Fig. 6). Patients with blood metal ions $>7 \mu \mathrm{g} / \mathrm{l}$ had a 6.5 times $(95 \%$ $\mathrm{Cl} 3.1-13.8 ; \mathrm{p}<0.0001)$ increased risk of revision than patients with levels $\leq 7 \mu \mathrm{g} / \mathrm{l}$.

\section{Discussion}

A relatively low prevalence of high blood metal ion concentrations following BHR was observed in this study compared to previous reports (33-35) with $9 \%$ of patients having blood metal ions above the MHRA upper limit of $7 \mu \mathrm{g} / \mathrm{l}$. This is reassuring given the cohort tested was considered at-risk of ARMD (all symptomatic patients and asymptomatic patients with specific clinical and/or radiological findings). It is likely the low prevalence of high blood metal ion concentrations observed is due to the use of a prosthesis with an established record implanted by experienced surgeons $(2-5,23)$. This study also demonstrated the best predictors of high blood metal ion concentrations ( $>7 \mu \mathrm{g} / \mathrm{l}$ ) following BHR were hips with small femoral head sizes $(38-44 \mathrm{~mm})$ and high acetabular inclinations $\left(>55^{\circ}\right)$.

The relationship between gender and femoral head size to hip resurfacing outcomes appears to be complex. Although most reports suggest smaller femoral head sizes are associated with increasing revision rates (36-38), 1 study observed that gender, and not femoral head size, significantly increased the risk of hip resurfacing revision for ARMD (17). With regards to blood metal ion concentrations, the present study demonstrated that although females and hips with small femoral head sizes have significantly higher blood metal ion concentrations, femoral head size was most influential $\left(R^{2}=8 \%\right.$ for Co and $R^{2}=11 \%$ for $\left.C r\right)$. These findings are supported by studies demonstrating higher blood metal ions in patients with smaller femoral head sizes for various hip resurfacing designs $(39,40)$. Our findings regarding blood metal ions support those relating to revision rates reported by the Australian Joint Registry (41) and another study involving BHR patients (36), with both demonstrating hip resurfacing revision rates were independent of gender once femoral component size was accounted for. Anatomical differences between genders are likely to be responsible for the interactions between gender and femoral head size as smaller components are most often implanted in females (11). We show femoral head size to be the most important factor for high blood metal ions following BHR though recognise the majority of these patients will be female.

This study observed significantly higher blood metal ion concentrations in patients with acetabular inclinations above $55^{\circ}$. These findings have been reported with a range of different hip resurfacing implants and it is suspected the raised concentrations are because of an increased risk of edge-loading with higher inclination angles $(16,39)$. However, when using linear regression acetabular inclination accounted for a significant but small variation in blood metal ions $\left(R^{2}=4 \%\right.$ for both $C o$ and $C r$ ). In addition to femoral head size it is likely other factors may be important in contributing to high blood metal ion concentrations, such as implant metallurgy. In contrast to our findings with the BHR a recent large study of a metal-on-metal hip replacement system no longer in clinical use demonstrated the association between acetabular inclination angle and blood cobalt concentration only reached significance with small femoral component sizes (34). The authors concluded the high implant failure rate was more likely related to design flaws rather than modifiable factors. 
TABLE IV - Details of 15 patients with blood metal ions above $7 \mu \mathrm{g} / \mathrm{l}$ undergoing revision for adverse reactions to metal debris

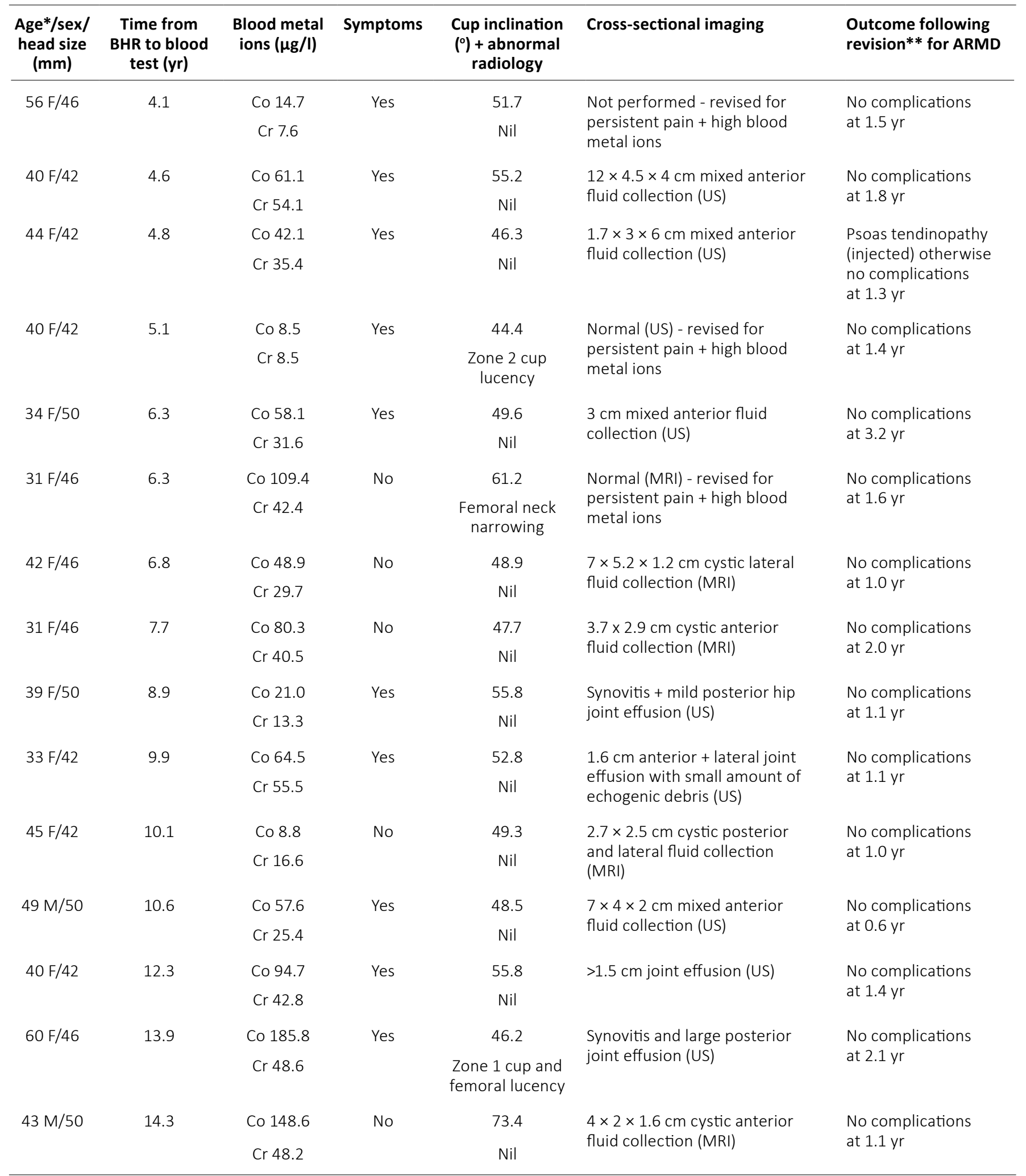

*Age at blood metal ion sampling.

**All 15 hips underwent revision of both hip resurfacing components to primary total hip replacement components using a non-metal-on-metal bearing articulation.

$\mathrm{ARMD}=$ adverse reactions to metal debris; $\mathrm{BHR}=$ Birmingham Hip Resurfacing; $\mathrm{Co}=$ cobalt; $\mathrm{Cr}=\mathrm{chromium} ; \mathrm{F}=$ female; $\mathrm{M}=\mathrm{male} ; \mathrm{MRI}=$ magnetic resonance imaging; US = ultrasound. 


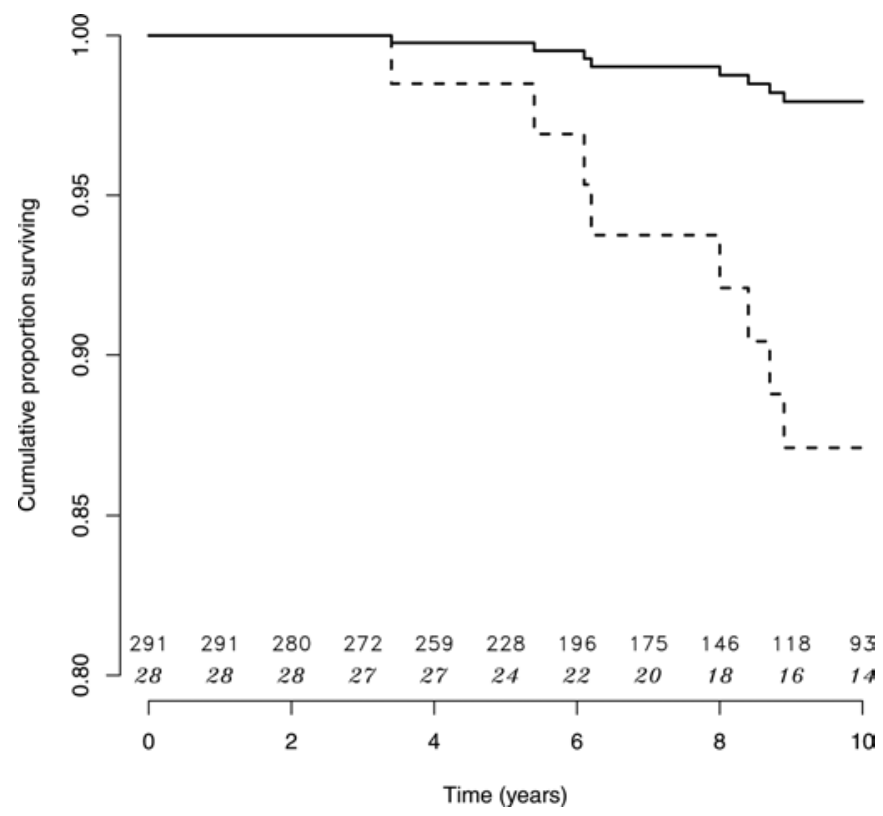

Fig. 6 - Cox-proportional hazards model comparing implant survival between patients with high $(>7 \mu \mathrm{g} / \mathrm{l})$ and low $(\leq 7 \mu \mathrm{g} / \mathrm{l})$ blood metal ion concentrations. Dashed line $=$ blood metal ion concentrations $>7 \mu \mathrm{g} / \mathrm{l}$; Solid line = blood metal ion concentrations $\leq 7 \mu \mathrm{g} / \mathrm{l}$; numbers on horizontal axis represent the number of hips at risk each year for the respective blood metal ion group (non-italic top row $\leq 7 \mu \mathrm{g} / \mathrm{l}$, and italic bottom row $>7 \mu \mathrm{g} / \mathrm{l})$.

In the present study the best predictors of high blood metal ions following BHR were hips with high acetabular inclinations $\left(>55^{\circ}\right)$ and small femoral head sizes $(38-44 \mathrm{~mm})$. It is therefore recommended this subgroup of BHR patients undergo screening for ARMD using blood metal ion sampling, even if asymptomatic. However, as these parameters only identified $36 \%$ of all patients with high blood metal ion concentrations it is recognised other investigations, such as cross-sectional imaging, are important when ARMD is suspected but blood metal ion concentrations are $7 \mu \mathrm{g} / \mathrm{l}$ or below.

Although the present cohort was considered an at-risk group for ARMD, implant survival at 10 -years (91\%) was comparable to that from independent centres (range 87\%-95\%) reporting on BHRs performed in all-comers rather than an exclusively at-risk group $(2,3,5,35)$. This study also demonstrated raised blood metal ion concentrations were associated with a significantly higher risk of implant failure ( 6.5 times increased risk of revision if $>7 \mu \mathrm{g} / \mathrm{l}$ versus $\leq 7 \mu \mathrm{g} / \mathrm{l}$ ) which supports previous findings (42).

This study has recognised limitations. First, the findings reported are based on a non-consecutive series of patients which may introduce selection bias. As patients undergoing blood metal ion sampling were mostly symptomatic (median OHS 31.0/48) many patients with well-functioning implants were not tested given the good long-term outcomes we have reported with the BHR (4). The true prevalence of raised blood metal ions in all BHRs performed at this centre may therefore differ to that reported here. Second, it is recognised complex interactions exist between the positioning of the acetabular and femoral components (18), which have been demonstrated to affect blood metal ions $(16,39)$. Although acetabular inclination was assessed, other factors which may affect blood metal ion concentrations such as acetabular anteversion and combined anteversion were not assessed, as it was not possible to measure these accurately using the software available. These variables may also have been useful in identifying patients with high blood metal ions. Third, the presence of other metal implants in the body was not used as an exclusion criterion. Some similar studies have made patient exclusions on this basis (43) whilst others have not $(40,44)$. Finally, although the BHR is the most popular resurfacing device implanted in England and Wales (23) the study findings may not be applicable to other hip resurfacing devices with different radial clearances, coverage arcs, and metallurgy $(7,19)$.

\section{Conclusions}

If blood metal ion concentrations are used for screening hip resurfacing patients for ARMD it is recommended the subgroup to target are those with femoral head sizes of $44 \mathrm{~mm}$ or less and acetabular component inclinations over $55^{\circ}$. As smaller femoral head sizes tend to be implanted in females it is recognised the population to be screened will predominantly be female. It is recognised our findings may not be applicable to all hip resurfacing devices, therefore these findings require validation in hip resurfacing cohorts at other centres prior to any widespread implementation as part of screening for ARMD.

\section{Acknowledgment}

The authors would like to thank The Royal College of Surgeons of England and The Arthritis Research Trust, which have provided one of the authors with funding in the form of a Surgical Research Fellowship.

\section{Disclosures}

Financial support: GSM: has received financial support in the form of a Surgical Research Fellowship from The Royal College of Surgeons of England and The Arthritis Research Trust. PBP, RBCT, DJD: Funding received by the institution from Smith and Nephew for maintaining the hospital database, which was used for this study and other projects.

Conflict of interest: FB: Salary paid by Smith and Nephew. The other authors have no conflicts of interest to declare.

\section{References}

1. Amstutz HC, Takamura KM, Le Duff MJ. The effect of patient selection and surgical technique on the results of Conserve ${ }^{\circledR}$ Plus hip resurfacing-3.5- to 14-year follow-up. Orthop Clin North Am. 2011;42(2):133-142, vii.

2. Coulter G, Young DA, Dalziel RE, Shimmin AJ. Birmingham hip resurfacing at a mean of ten years: results from an independent centre. J Bone Joint Surg Br. 2012;94(3):315-321.

3. Murray DW, Grammatopoulos G, Pandit H, Gundle R, Gill HS, McLardy-Smith $P$. The ten-year survival of the Birmingham hip resurfacing: an independent series. J Bone Joint Surg $\mathrm{Br}$. 2012;94(9):1180-1186. 
4. Matharu GS, McBryde CW, Pynsent WB, Pynsent PB, Treacy RB. The outcome of the Birmingham Hip Resurfacing in patients aged $<50$ years up to 14 years post-operatively. Bone Joint J. 2013;95(9):1172-1177.

5. Van Der Straeten C, Van Quickenborne D, De Roest B, Calistri A, Victor J, De Smet K. Metal ion levels from well-functioning Birmingham Hip Resurfacings decline significantly at ten years. Bone Joint J. 2013;95(10):1332-1338.

6. Carrothers AD, Gilbert RE, Jaiswal A, Richardson JB. Birmingham hip resurfacing: the prevalence of failure. J Bone Joint Surg Br. 2010;92(10):1344-1350.

7. Langton DJ, Joyce TJ, Jameson SS, et al. Adverse reaction to metal debris following hip resurfacing: the influence of component type, orientation and volumetric wear. J Bone Joint Surg Br. 2011;93(2):164-171.

8. De Smet KA, Van Der Straeten C, Van Orsouw M, Doubi R, Backers K, Grammatopoulos G. Revisions of metal-on-metal hip resurfacing: lessons learned and improved outcome. Orthop Clin North Am. 2011;42(2):259-269, ix.

9. Grammatopolous $\mathrm{G}$, Pandit $\mathrm{H}$, Kwon YM, et al. Hip resurfacings revised for inflammatory pseudotumour have a poor outcome. J Bone Joint Surg Br. 2009;91(8):1019-1024.

10. Munro JT, Masri BA, Duncan CP, Garbuz DS. High complication rate after revision of large-head metal-on-metal total hip arthroplasty. Clin Orthop Relat Res. 2014;472(2):523-528.

11. Haddad FS, Thakrar RR, Hart AJ, et al. Metal-on-metal bearings: the evidence so far. J Bone Joint Surg Br. 2011;93(5):572-579.

12. Sidaginamale RP, Joyce TJ, Lord JK, et al. Blood metal ion testing is an effective screening tool to identify poorly performing metalon-metal bearing surfaces. Bone Joint Res. 2013;2(5):84-95.

13. Medical and Healthcare Products Regulatory Agency (MHRA) (2012). Medical Device Alert: all metal-on-metal (MoM) hip replacements. MDA/2012/036. Available at: http://www.mhra. gov.uk/. Last accessed on $20^{\text {th }}$ April 2015.

14. Hart AJ, Satchithananda K, Liddle AD, et al. Pseudotumors in association with well-functioning metal-on-metal hip prostheses: a case-control study using three-dimensional computed tomography and magnetic resonance imaging. J Bone Joint Surg Am. 2012;94(4):317-325.

15. Bisschop R, Boomsma MF, Van Raay JJ, Tiebosch AT, Maas M, Gerritsma CL. High prevalence of pseudotumors in patients with a Birmingham Hip Resurfacing prosthesis: a prospective cohort study of one hundred and twenty-nine patients. J Bone Joint Surg Am. 2013;95(17):1554-1560.

16. De Haan R, Pattyn C, Gill HS, Murray DW, Campbell PA, De Smet K. Correlation between inclination of the acetabular component and metal ion levels in metal-on-metal hip resurfacing replacement. J Bone Joint Surg Br. 2008;90(10):1291-1297.

17. Glyn-Jones S, Pandit H, Kwon YM, Doll H, Gill HS, Murray DW. Risk factors for inflammatory pseudotumour formation following hip resurfacing. J Bone Joint Surg Br. 2009;91(12):1566-1574.

18. Grammatopoulos G, Pandit H, Glyn-Jones S, et al. Optimal acetabular orientation for hip resurfacing. J Bone Joint Surg Br. 2010;92(8):1072-1078.

19. Langton DJ, Jameson SS, Joyce TJ, Hallab NJ, Natu S, Nargol AV. Early failure of metal-on-metal bearings in hip resurfacing and large-diameter total hip replacement: $A$ consequence of excess wear. J Bone Joint Surg Br. 2010;92(1):38-46.

20. Treacy RB, McBryde CW, Pynsent PB. Birmingham hip resurfacing arthroplasty. A minimum follow-up of five years. J Bone Joint Surg Br. 2005;87(2):167-170.

21. Dawson J, Fitzpatrick R, Carr A, Murray D. Questionnaire on the perceptions of patients about total hip replacement. J Bone Joint Surg Br. 1996;78(2):185-190.

22. Medical and Healthcare Products Regulatory Agency (MHRA) (2010). Medical Device Alert: ASR $^{\mathrm{TM}}$ hip replacement implant manufactured by DePuy International Ltd. MDA/2010/069. Available at: http://www.mhra.gov.uk/. Last accessed on $20^{\text {th }}$ April 2015.

23. National Joint Registry for England and Wales: Tenth annual report 2013. Available at: http://www.njrcentre.org.uk. Last accessed on $20^{\text {th }}$ April 2015.

24. Lombardi AV Jr, Barrack RL, Berend KR, et al. The Hip Society: algorithmic approach to diagnosis and management of metalon-metal arthroplasty. J Bone Joint Surg Br. 2012;94(11)(Suppl A):14-18.

25. Pandit H, Glyn-Jones S, McLardy-Smith P, et al. Pseudotumours associated with metal-on-metal hip resurfacings. J Bone Joint Surg Br. 2008;90(7):847-851.

26. Bland JM, Altman DG. Measuring agreement in method comparison studies. Stat Methods Med Res. 1999;8(2):135-160.

27. Amstutz HC, Beaulé PE, Dorey FJ, Le Duff MJ, Campbell PA, Gruen TA. Metal-on-metal hybrid surface arthroplasty: two to six-year follow-up study. J Bone Joint Surg Am. 2004;86(1):28-39.

28. DeLee JG, Charnley J. Radiological demarcation of cemented sockets in total hip replacement. Clin Orthop Relat Res. 1976; (121):20-32.

29. Hing CB, Young DA, Dalziel RE, Bailey M, Back DL, Shimmin AJ. Narrowing of the neck in resurfacing arthroplasty of the hip: a radiological study. J Bone Joint Surg Br. 2007;89(8):1019-1024.

30. R Core Team. R: A language and environment for statistical computing. R Foundation for Statistical Computing, Vienna, Austria 2013.

31. Davda K, Lali FV, Sampson B, Skinner JA, Hart AJ. An analysis of metal ion levels in the joint fluid of symptomatic patients with metal-on-metal hip replacements. J Bone Joint Surg Br. 2011;93(6):738-745.

32. Matthies AK, Henckel J, Cro S, et al. Predicting wear and blood metal ion levels in metal-on-metal hip resurfacing. J Orthop Res. 2014;32(1):167-174.

33. Langton DJ, Sidaginamale RP, Joyce TJ, et al. The clinical implications of elevated blood metal ion concentrations in asymptomatic patients with MoM hip resurfacings: a cohort study. BMJ Open. 2013;3(3):e001541.

34. Emmanuel AR, Bergin KM, Kelly GE, McCoy GF, Wozniak AP, Quinlan JF. The effect of acetabular inclination on metal ion levels following metal-on-metal hip arthroplasty. J Arthroplasty. 2014;29(1):186-191.

35. Reito A, Puolakka T, Elo P, Pajamäki J, Eskelinen A. Outcome of Birmingham hip resurfacing at ten years: role of routine whole blood metal ion measurements in screening for pseudotumours. Int Orthop. 2014;38(11):2251-2257.

36. McBryde CW, Theivendran K, Thomas AM, Treacy RB, Pynsent $\mathrm{PB}$. The influence of head size and sex on the outcome of Birmingham hip resurfacing. J Bone Joint Surg Am. 2010; 92(1): 105-112.

37. Shimmin AJ, Walter $\mathrm{WL}$, Esposito $C$. The influence of the size of the component on the outcome of resurfacing arthroplasty of the hip: a review of the literature. J Bone Joint Surg Br. 2010;92(4):469-476.

38. Smith AJ, Dieppe P, Howard PW, Blom AW; National Joint Registry for England and Wales. Failure rates of metal-on-metal hip resurfacings: analysis of data from the National Joint Registry for England and Wales. Lancet. 2012;380(9855):1759-1766.

39. Langton DJ, Jameson SS, Joyce TJ, Webb J, Nargol AV. The effect of component size and orientation on the concentrations of metal ions after resurfacing arthroplasty of the hip. J Bone Joint Surg Br. 2008;90(9):1143-1151.

40. Parry MC, Eastaugh-Waring S, Bannister GC, Learmonth ID, Case CP, Blom AW. Blood levels of cobalt and chromium are inversely correlated to head size after metal-on-metal resurfacing arthroplasty. Hip Int. 2013;23(6):529-534. 
41. Australian Orthopaedic Association National Joint Replacement Registry, Hip and knee arthroplasty Annual Report 2008. Avialable at: https://aoanjrr.dmac.adelaide.edu.au/it/annualreports-2008. Last accessed on $20^{\text {th }}$ April 2015.

42. Hart AJ, Sabah SA, Sampson B, et al. Surveillance of Patients with Metal-on-Metal Hip Resurfacing and Total Hip Prostheses: A prospective cohort study to investigate the relationship between blood metal ion levels and implant failure. J Bone Joint Surg Am. 2014;96(13):1091-1099.
43. Van Der Straeten C, Grammatopoulos G, Gill HS, Calistri A, Campbell P, De Smet KA. The 2012 Otto Aufranc Award: The interpretation of metal ion levels in unilateral and bilateral hip resurfacing. Clin Orthop Relat Res. 2013;471(2):377-385.

44. Malek IA, King A, Sharma $H$, et al. The sensitivity, specificity and predictive values of raised plasma metal ion levels in the diagnosis of adverse reaction to metal debris in symptomatic patients with a metal-on-metal arthroplasty of the hip. J Bone Joint Surg Br. 2012;94(8):1045-1050. 